\title{
Predictive Factors of Abdominal Compartment Syndrome in Neonatal Age
}

\author{
Ingrid Anne Mandy Schierz, MD ${ }^{1}$ Mario Giuffrè, MD ${ }^{1}$ Ettore Piro, MD ${ }^{1}$ Rita Ortolano, MD ${ }^{1}$ \\ Fortunato Siracusa, MD² Giuseppa Pinello, MD ${ }^{1}$ Simona La Placa, MD ${ }^{1}$ Giovanni Corsello, MD ${ }^{1}$
}

${ }^{1}$ Dipartimento Universitario Materno Infantile, Unità Operativa

Address for correspondence Ingrid Anne Mandy Schierz, MD, Via Complessa di Neonatologia e Terapia Intensiva Neonatale, Azienda Ospedaliera Universitaria Policlinico Paolo Giaccone, Università degli Studi di Palermo, Palermo, Italy

2 Unità Operativa di Chirurgia Pediatrica, Dipartimento Universitario Materno Infantile, Azienda Ospedaliera Universitaria Policlinico Paolo Giaccone, Università degli Studi di Palermo, Palermo, Italy

Alfonso Giordano, 3, 90127 Palermo, Italy (e-mail: inschier@tin.it).

Am J Perinatol 2014;31:49-54.

\begin{abstract}
In the pediatric population, abdominal compartment syndrome (ACS) is a known complication of abdominal wall defect repair. However, there are only few reports on ACS in newborns and only a proposal of critical intra-abdominal pressure value (IAP) in term newborns, absent in preterm newborns. Although the prevalent clinical sign is tense abdominal distension, it may be difficult to distinguish ACS from pathologies that will not require decompression. The purpose of this study was to identify predictors for ACS and therefore morbidity or mortality indicators. We reviewed newborns presenting with tense abdominal distension and end organ failure. Anamnestic, clinical, laboratory, and instrumental investigations were analyzed to extrapolate predictors. Outcomes were compared with a control group. The incidence of

Keywords

- lactate

- multiple end-organ failure

- intra-abdominal hypertension ACS in our neonatal intensive care unit was $5 \%$ in the overall population of babies, $16 \%$ in tracheal-ventilated newborns, and $57 \%$ in infants with abdominal wall defects. We found that, with onset of acidosis or high gastric residuals, the lactate values will be predictive for mortality. We can also suggest paying particular attention to high lactate values just at the onset of distension, in infants with more advanced gestational age, with previously surgical repair, to determine early surgical intervention independently of a specific IAP measurement.
\end{abstract}

Compartment syndrome, clinically more common in the extremities, is recognized also as a life-threatening entity in the peritoneal cavity. This cavity represents a compliancelimited anatomic space in which both a prolonged elevated pressure and ischemia can cause multiple end-organ dysfunction. The incidence of abdominal compartment syndrome (ACS) in pediatric intensive care units is estimated at approximately $1 \%{ }^{1,2}$ but in ventilated children it was retrospectively calculated as $18.7 \%{ }^{3}$ Mortality is high, at 40 to $60 \%{ }^{1,2}$ According to the World Society of ACS definition, in adults an ACS is defined as the combination of intra-abdominal hypertension (IAH), measured as increased intravesical pressure (IVP) above $20 \mathrm{~mm} \mathrm{Hg}$, and progressive new end-organ

received

July 5,2012

accepted after revision

December 31, 2012

published online

March 1, 2013 dysfunction, with or without an abdominal perfusion pressure (APP) less than $60 \mathrm{~mm} \mathrm{Hg}{ }^{4}$ In children with a normally lower arterial pressure, ACS will onset at values as low as $\sim 13 \mathrm{~mm} \mathrm{Hg}{ }^{5}$ IAH can increase intracranial pressure and reduce splanchnic, hepatic, and portal perfusion leading to bowel ischemia, elevated interleukin cytokine release, and refractory metabolic acidosis. Although tense abdominal distension, caused by bowel edema and bowel distension, is the main sign on physical examination, especially in neonatal age, it will be difficult to distinguish from other pathologies that will not urge surgical decompression. The aim of this study was to describe the occurrence of ACS in critically ill newborns and to identify possible predictive factors.
Copyright (c) 2014 by Thieme Medical Publishers, Inc., 333 Seventh Avenue, New York, NY 10001, USA. Tel: +1(212) 584-4662.
DOI http://dx.doi.org/ 10.1055/s-0033-1334447. ISSN $0735-1631$. 


\section{Materials and Methods}

A retrospective chart review, from a neonatal intensive care unit (NICU) with reference centre for genetic and pediatric surgery, was conducted between 2010 and 2011. Newborns [range from $25^{+2}$ to $39^{+5}$ weeks of gestational age (GA) and from 760 to $3,120 \mathrm{~g}$ of birth weight] presenting with tense abdominal distension and end-organ failure were enrolled. Anamnestic and clinical (-Table 1), laboratory and instrumental examinations at five stages (admission, first abdominal distension, marked edema, onset of acidosis defined as $\mathrm{pH}<7.20$, and continuous bicarbonate correction) as well as before and after surgery were reviewed. Outcome and days of hospital stay were collected in this group and in a control group consisting of all other ventilated newborns. The diagnosis of ACS was made if the tense abdominal distension with $\mathrm{IAH}$, evaluated indirectly by decreased ratio of dual, postductal pulse oximetry monitoring on right foot and left hand, ${ }^{6}$ led to new-onset end-organ dysfunction in two or more organ systems, ${ }^{3}$ including oliguria $(<0.5 \mathrm{~mL} / \mathrm{kg} / \mathrm{h})$, new-onset or deterioration of respiratory distress (partial pressure of oxygen $\left(\mathrm{paO}_{2}\right)$ /fraction of inspired oxygen ratio $<150$ or high peak airway pressure relatively to GA), hypotension (in term newborn persistent mean blood pressure lower than 2 standard deviations under the normative, and in preterm simplified as mean blood pressure lower than the number of GA), or low cardiac index $\left(<1.7 \mathrm{~L} / \mathrm{min} / \mathrm{m}^{2}\right)$ despite resuscitation. ${ }^{7}$ Most assessments of cardiac index were performed by multiplying the time-velocity integral on the basis of a pulsed Doppler tracing in the left ventricular outflow tract proximal to the aortic valve leaflets by its cross-sectional area and heart rate, and then divided by body surface area. Data from Mmode Teichholz equation or from right ventricular assessment were also considered. IVP measurements were acquired perioperatively during primary or stepwise abdominal wall defect repair, but not routinely in NICU.

For the statistical analysis data were transferred from a Microsoft Excel sheet to the R Commander "Palermo software package." Wilcoxon's rank-sum test was used to explore the relationship between adverse outcome and biochemical parameters, Fisher exact test for categorical variable, and logistic regression analysis to identify independent factors for mortality and morbidity. A probability value of $p<0.05$ was considered statistically significant.

\section{Results}

We observed 21 events in 17 newborns fulfilling inclusive criteria. Male newborns were more affected than female ones (68\% versus $32 \%$ ). The incidence of ACS in our NICU was $5 \%$ (21/403) in the overall population, 16\% (21/130) in trachealventilated newborns, and 57\% (4/7) in abdominal wall defect repairs. The etiology of ACS was as follows: primary ACS in 57\% (12/21 newborns: 1 with Cantrell pentalogy, 1 with Edward syndrome, and 2 with isolated abdominal wall defects, others with ileus or intestinal perforation), secondary ACS in 24\% (5/21: 4 with sepsis, 1 with Nager syndrome, 1 with Down syndrome), and tertiary ACS in 19\% (4/21). Apart from the primary causes of ACS as congenital abdominal wall defect (4) or intestinal atresia/stenosis (3), other concomitant pathologies were chromosomal disorders (2), cardiopathy (9), diaphragmatic defect (2), esophageal atresia Vogt I and III (2), mucoviscidosis (1), hypothyroidism (1), and subsequently scrotal hernia (6), and retinopathy of prematurity (ROP) grade II to III (7).

Initial treatment was conservative, consisting of left-side anti-Trendelenburg body position for vena cava relief, frequent gastric and rectal gas evacuations, analgosedation, and optimized ventilatory and cardiovascular support. Six patients reached surgical decompression, but two of the babies with secondary and two of tertiary ACS had a fulminating course and died prior to surgical intervention. The total mortality was $29 \%$. In the tracheal ventilated non-ACS group, with similar weight and GA distribution, the mortality was the half $(p=0.4)$. Mean hospital stay in the survivors was longer in the ACS respect to the non-ACS group (53 versus 26 days; $p=0.0008$ ).

All newborns with ACS had a poor Apgar score (mean 6 and 8 at 1 and 5 minutes, respectively); however, 1-minute Apgarscore was not correlated with lactate or base excess values at admission ( $p=0.64$ and 0.2 ). First abdominal symptoms appeared at day 14 (mean), and ACS was manifest at a mean age of 15 days of life. The mean GA was 33 weeks. We found a trend of more risk of multiorgan failure and death (-Tables 2 and $\mathbf{3}$ ) in newborns with a more advanced GA (median 36 versus 30 gestational weeks; $p=0.09$ ), with a congenital cause of ACS ( $p=0.04$ ) who received bicarbonate correction $(p=0.05)$ and inotropes $(p=0.04)$ and had high values of lactate before surgery (median 4.3 versus 1.9; $p=0.07$ ). High lactate levels just at admission were correlated with late abdominal distension $(p=0.08)$ and with progressive more marked base excess during manifest ACS $(p=0.0005)$. Newborns with late distension had higher lactate values also in the stages of distension and acidosis ( $p=0.02$ and 0.005 , respectively). Furthermore, lactate values at onset of abdominal distension were higher in babies that would have more severe events (median 2.2 versus 4.7; $p=0.06$ ), but were not correlated with death (median 2.4 versus $5.9 ; p=0.2$ ). Only in successive stages with onset of acidosis were the lactate values predictive for mortality (median 4 versus $10.1 ; p=0.017$ ), as well as in the presence of high gastric residuals (median 2 versus 9.25; $p=0.017$ ). With respect to primary ACS, the lactate values were higher in newborns with secondary and tertiary ACS during stages of distension (median 1.2 versus 2.5 and $7.15 ; p=0.02$ ) and acidosis (median 3.4 versus 5.9 and $7.65 ; p=0.2$ ). Patients with cardiopathy had a predisposition to lower lactate levels during stages of distension (median 2.2 versus $3.1 ; p=0.13$ ) and acidosis (median 4 versus $8.3 ; p=0.2$ ). Finally, all patients who died had a tendency to low diuresis just at admission (median 0.5 versus $1.5 ; p=0.3$ ) and persistent low diuresis at onset of abdominal distension (median 1.6 versus $3.1 ; p=0.3$ ), as well as early low levels of albumin (median 2.2 versus $2.9 ; p=0.23$ and median 2 versus $2.7 ; p=0.18$ ). In the advanced stage of the disease, they showed altered indices of infection (positive C-reactive protein values). Nevertheless, we did not find correlations with creatinine levels, 
Predictive Factors for ACS Schierz et al. 51

\begin{tabular}{|c|c|c|c|c|c|c|c|c|c|c|c|c|c|c|c|c|c|c|c|c|c|}
\hline 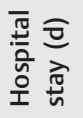 & $m$ & & $\stackrel{\text { ำ }}{\forall}$ & & $\stackrel{\infty}{m}$ & & $\bar{m}$ & $\stackrel{m}{r}$ & $\stackrel{n}{m}$ & in & $\stackrel{m}{r}$ & & $\stackrel{\curvearrowright}{\cong}$ & $m$ & 은 & $\underset{\sim}{\stackrel{\Xi}{ }}$ & $\stackrel{\bullet}{\sim}$ & ต & $\stackrel{v}{\sim}$ & $\stackrel{\circ}{\circ}$ & రా \\
\hline 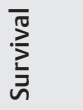 & $z$ & $>$ & $>$ & $>$ & $z$ & $>$ & $z$ & $>$ & $>$ & $>$ & $>$ & $>$ & $>$ & $>$ & $>$ & $>$ & $>$ & $z$ & $z$ & $>$ & $>$ \\
\hline 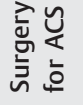 & $>$ & $z$ & $>$ & $z$ & $z$ & $>$ & $z$ & $>$ & $>$ & $z$ & $z$ & $>$ & $>$ & $z$ & 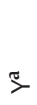 & $z$ & $z$ & $z$ & $z$ & $z$ & $z$ \\
\hline 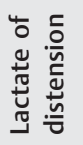 & $\stackrel{\llcorner}{\sim}$ & 广户 & $\nabla$ & $\bar{m}$ & $\stackrel{\llcorner}{\sim}$ & $\hat{0}$ & $\begin{array}{l}\infty \\
\infty\end{array}$ & 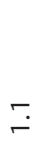 & - & $\stackrel{\sigma}{0}$ & $\stackrel{m}{r}$ & $\hat{\sim}$ & $\begin{array}{l}\text { ᄂ? } \\
\text { เं }\end{array}$ & $\stackrel{\sim}{r}$ & $\stackrel{\infty}{r}$ & - & $\stackrel{\llcorner}{\sim}$ & $\stackrel{m}{r}$ & $\bar{\sigma}$ & $\stackrel{+}{\sim}$ & $\underset{\sim}{\sim}$ \\
\hline
\end{tabular}

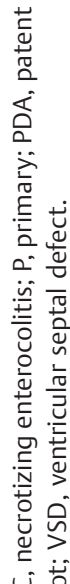

$\div \frac{0}{\underline{0}}$

ठั

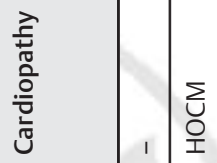

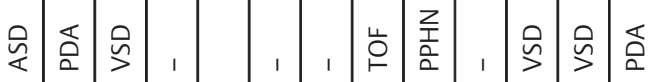
峞

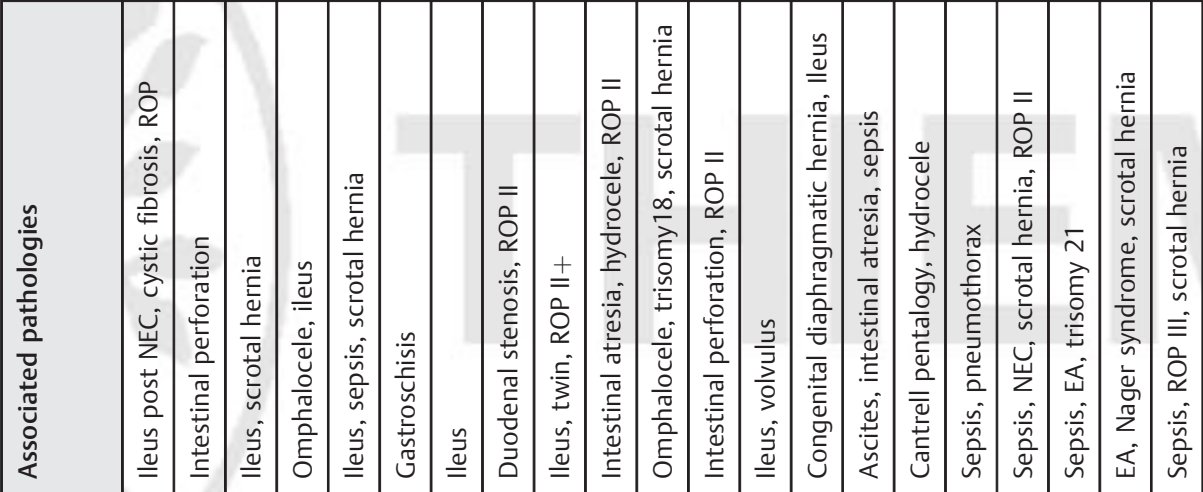

$+\frac{\pi}{2}$

$\longrightarrow$

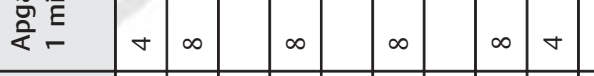

으

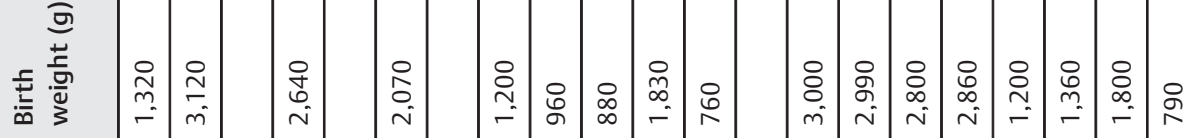

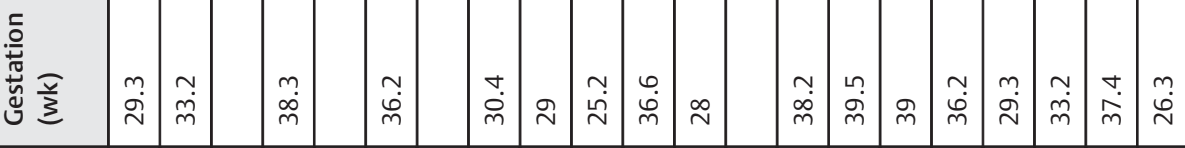

竞

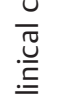
列

它

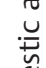

$\stackrel{\text { E }}{E}$

突

कृ

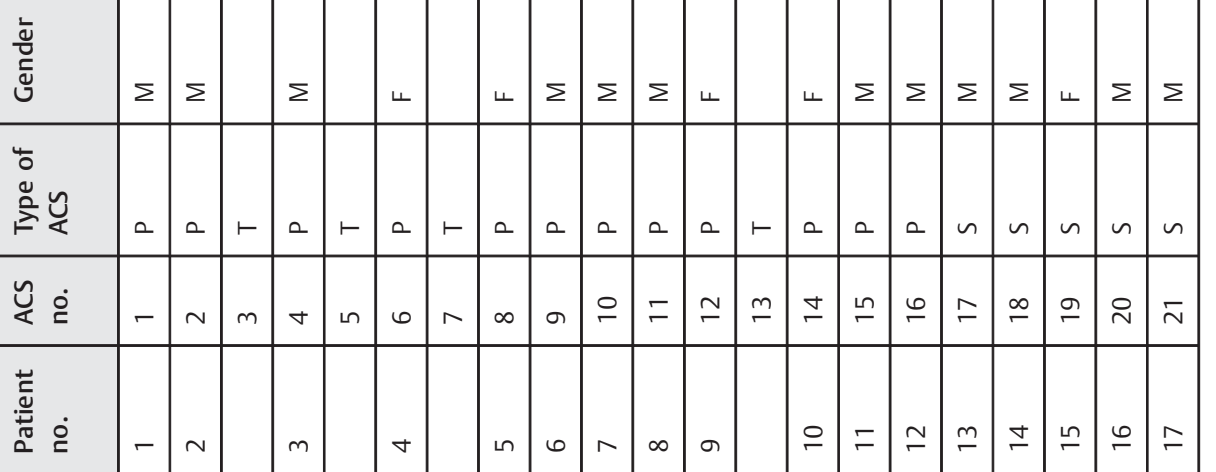

荳苍

हो

흔

总离

空密

芦

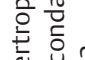

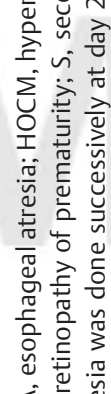

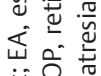

苞产

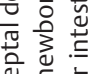

这

范范要

कि 은

ثิ

흔

会竕

党

茯

造产离

है

음 중 
Table 2 Median for clinical and biohumoral variables in newborns who died/survived

\begin{tabular}{|c|c|c|c|}
\hline Variables & Survivors & Deceased & $p$ value \\
\hline \multicolumn{4}{|l|}{ Anamnestic parameters } \\
\hline Gestational age (wk) & 30 & 36 & 0.09 \\
\hline Apgar 1 min & 5 & 8 & 0.05 \\
\hline Birth weight $(\mathrm{g})$ & 1,200 & 2,070 & 0.33 \\
\hline \multicolumn{4}{|l|}{ Cardiovascular parameters at distension } \\
\hline Heart rate (beats/min) & 128 & 122 & 0,82 \\
\hline Cardiac index $\left(\mathrm{L} / \mathrm{min} / \mathrm{m}^{2}\right)$ & 3.2 & 2.7 & 0.71 \\
\hline Mean arterial pressure at distension $(\mathrm{mm} \mathrm{Hg})$ & 49 & 51 & 0.87 \\
\hline \multicolumn{4}{|l|}{ Respiratory parameters at distension } \\
\hline $\mathrm{FlO}_{2}(\%)$ & 0.25 & 0.26 & 0.77 \\
\hline $\mathrm{PCO}_{2}(\mathrm{~mm} \mathrm{Hg})$ & 43.2 & 40.9 & 0.75 \\
\hline $\mathrm{PIP}\left(\mathrm{cm} \mathrm{H}_{2} \mathrm{O}\right)$ & 22 & 17.5 & 0.23 \\
\hline Oxygenation index & 5 & 4.05 & 0.65 \\
\hline \multicolumn{4}{|l|}{ Renal parameters at distension } \\
\hline Urine output $(\mathrm{mL} / \mathrm{kg} / \mathrm{h})$ & 3.1 & 1.6 & 0.28 \\
\hline Creatinine level $(\mathrm{mg} / \mathrm{dL})$ & 0.61 & 0.6 & 0.55 \\
\hline \multicolumn{4}{|l|}{ Metabolic parameters } \\
\hline $\mathrm{pH}$ at distension & 7.29 & 7.22 & 0.18 \\
\hline $\mathrm{BE}$ at distension $(\mathrm{mmol} / \mathrm{L})$ & -3.7 & -6.75 & 0.43 \\
\hline Lactate at distension $(\mathrm{mmol} / \mathrm{L})$ & 2.4 & 5.9 & 0.2 \\
\hline Lactate at acidosis & 4 & 10.1 & 0.017 \\
\hline Lactate at onset of gastric residual & 2 & 9.25 & 0.017 \\
\hline Lactate preintervention & 1.9 & 4.3 & 0.07 \\
\hline Lactate postintervention & 3.3 & 6.6 & 0.14 \\
\hline
\end{tabular}

Abbreviations: $\mathrm{BE}$, base excess; $\mathrm{CO}_{2}$, partial pressure of carbon dioxide; $\mathrm{FlO}_{2}$, fraction of inspired oxygen; PIP, peak inspiratory pressure.

cardiac index, or mean values of respiratory distress at any stage until overwhelming end-organ failure.

\section{Discussion}

In the pediatric population, ACS is a known complication of repair of abdominal wall defects (gastroschisis or omphalocele). Omphalocele has been called "a prototype for ACS." However, there are only few reports dealing ACS in newborns and only a proposal of critical abdominal pressure value in newborns. ${ }^{5,9-13}$ We present a retrospective study of 21 cases of clinical ACS in newborns with the aim to extrapolate predictive factors. Compared with adults and older children, leading causes of ACS in newborns are different and vary from congenital gastrointestinal atresia and abdominal wall defects to ileus and sepsis. According to the described clinical evolution in older children, ${ }^{11}$ we also confirm a high frequency of associated or sequential pathologies, emphasizing a multifactorial process for onset of ACS. We have also noticed a high frequency of scrotal hernia as an indirect sign of elevated abdominal pressure. The cascade of elevated interleukins-cytokines and free radical release, the lack of nutri- tional protective factors, and the impeding venous return from cerebrum-sensorial circuit are considered responsible for more severe evolution of ROP in susceptible newborns. According to these data, we have found an advanced ROP in all preterm newborns with ACS less than 33 gestational weeks.

The incidence of ACS of 5\% in NICU is higher than expected. This data might be overestimated in our study, because of uncommonly high number of surgical newborns on our ward and in relation to the incomplete IVP measurements. However, we believe that our inclusive criterions were comparable with other studies, taking in account that a single IVP peak value will not be so clearly confident as the clinical presentation. ${ }^{1,3,5,9-11,14}$ Several studies have been performed to determine the most accurate method of measuring IAP in children. The gold standard, as in adults, is the measurement of IVP, frequently used during surgery for closure of abdominal wall defects. However, no technique is currently used routinely in NICU, and the range of normal IVP is not determined into neonatal age. The values used in adult and pediatric population to decide to practice an abdominal decompression are not applicable in newborns because of 
Table 3 Median for clinical and biohumoral variables for newborns with or without CCB

\begin{tabular}{|c|c|c|c|}
\hline Variable & Without CCB & With CCB & $p$ value \\
\hline \multicolumn{4}{|l|}{ Cardiovascular parameters at distension } \\
\hline Heart rate (beats/min) & 126 & 123 & 0.85 \\
\hline Cardiac index $\left(\mathrm{L} / \mathrm{min} / \mathrm{m}^{2}\right)$ & 3.1 & 2.8 & 0.79 \\
\hline Mean arterial pressure at distension $(\mathrm{mm} \mathrm{Hg})$ & 49 & 50 & 0.9 \\
\hline \multicolumn{4}{|l|}{ Respiratory parameters at distension } \\
\hline $\mathrm{F}_{10}(\%)$ & 0.25 & 0.25 & 0.93 \\
\hline $\mathrm{pCO}_{2}(\mathrm{~mm} \mathrm{Hg})$ & 43 & 39 & 0.43 \\
\hline $\mathrm{PIP}\left(\mathrm{cm} \mathrm{H} \mathrm{H}_{2} \mathrm{O}\right)$ & 22 & 20 & 0.35 \\
\hline Oxygenation index & 4.2 & 5.6 & 0.69 \\
\hline \multicolumn{4}{|l|}{ Renal parameters at distension } \\
\hline Urine output (mL/kg/h) & 3.7 & 3.1 & 0.54 \\
\hline Creatinine level (mg/dL) & 0.61 & 0.6 & 0.73 \\
\hline \multicolumn{4}{|l|}{ Metabolic parameters } \\
\hline $\mathrm{pH}$ at distension & 7.29 & 7.23 & 0.03 \\
\hline $\mathrm{BE}$ at distension $(\mathrm{mmol} / \mathrm{L})$ & -2.9 & -5.5 & 0.11 \\
\hline Lactate at distension (mmol/L) & 2.2 & 4.7 & 0.06 \\
\hline Lactate at acidosis & 2.2 & 9.1 & 0.001 \\
\hline Lactate at gastric residual & 1.9 & 4.7 & 0.02 \\
\hline Lactate preintervention & 1.5 & 4.7 & 0.009 \\
\hline Lactate postintervention & 2.6 & 7.4 & 0.004 \\
\hline
\end{tabular}

Abbreviations: $\mathrm{BE}$, base excess; $\mathrm{CCB}$, continuous correction with bicarbonates; $\mathrm{CO}_{2}$, partial pressure of carbon dioxide; $\mathrm{FlO}_{2}$, fraction of inspired oxygen; PIP, peak inspiratory pressure.

the variable abdomen compliance and lower normal systemic mean pressure.

The mortality of $29 \%$ is fortunately fewer than observed in adults or older children ${ }^{1-3,5,9-11,14}$ and is probably explained by more compliant abdominal cavities in newborns. This would also explain why patients with secondary ACS or with more advanced GA could not tolerate IAH as well as newborns with abdominal wall defects, in particularly with pentalogy of Cantrell. ${ }^{15}$ Our patient with Cantrell pentalogy, once recovered from primary ACS, tolerated subsequent IAP of more than $40 \mathrm{~mm} \mathrm{Hg}$ preserving APP by arterial hypertension (secondary to documented hyperaldosteronism) without manifesting new organ failures and without development of tertiary ACS.

We could not find correlations with respiratory distress, because different GAs and underlying pathologies did not allow for a comparable ventilation approach. Our data did not allow us to explain why newborns with cardiopathy have a lower lactate level during onset of ACS and, according to our result, a better survival.

Despite that lactate value at admission or initial abdominal distension is not correlated with mortality, they will predict anyway an unfavorable course as they represents an early marker of tissue hypoperfusion and hypoxia in the early stages of intestinal distension. Several studies of pediatric and neonatal patients have demonstrated that the serum lactate is a reliable indicator of intestinal ischemia by differ- ent causes. ${ }^{16}$ Other clinical and laboratory tests will be sensitive in detecting abnormalities of tissue perfusion during ACS only after sustained periods of inadequate perfusion, as evidenced by deterioration of some biochemical values only in the late irreversible stages ( $\mathrm{pH}$, base excess). In confirming this, we could note a lack of correlation between these values and lactate at the early stages of IAH.

Infants with delayed clinical manifestations are probably in an advanced stage of organ injury, as evidenced by the high values of lactate in these cases during abdominal distension. In fact, it is often the first warning sign in an infant appearing reactive and well ventilated, because acidosis is initially sufficiently compensated by the kidneys. In newborns who previously underwent a surgical repair, the absence of concrete classical clinical and radiological signs makes it difficult to distinguish ACS from the frequent and transitory postoperative ileus or from immaturity of intestinal motility. Especially in these patients, lactate can be a useful indicator.

All infants who died presented in the end stage of ACS with clinical signs and positive indices of systemic sepsis. Indeed, the pathophysiological events that occur during ACS lead to a severe systemic inflammatory response causing intestinal hypoperfusion and increasing permeability of the mucosa. This, in turn, facilitates bacterial translocation, which may contribute to the development of septic complication and organ failure. The ischemic intestinal damage is also correlated indirectly with signs of altered intestinal motility. 
The presence of gastric residuals associated with elevated lactate levels in infants who died reflects the relationship between increased IAP and inhibition of electrical and mechanical motor activity in intestinal muscles, based on an ischemic-reperfusional model. ${ }^{17}$

Oliguria is one of the first visible sign of IAH, because changes in the IAP will have a greater impact upon renal function and urine production (direct compression of the renal parenchyma and decreased kidney perfusion due to decreased cardiac output). In our study, the reduction in urine output and changes in serum indices of renal function, even though altered in the most severely ill infants, were not significant, probably due to early specific treatment for underlying disease (fluids and perfusional drugs), before marked abdominal distension. These advanced treatments probably also preserved cardiac output, ${ }^{18}$ explaining why we did not find significant alterations in cardiac index in our patients until end-organ failure.

\section{Conclusion}

Infants with ACS represent a complex challenge because the disease causes rapid and unexpected deterioration of clinical condition. The measurement of IAP, though remaining the gold standard for diagnosis of ACS, is not routinely performed in newborns, and there is a lack of data to define the range of normal values in this age group. Because there is no better outcome even in adult patients with measurement of IAP, the management of a suspected ACS in newborns can only be based on clinical and biochemical predictors for evolution to end-organ dysfunction. We therefore recommend paying particular attention in term or near-term infants with high lactate values at the onset of distension who previously underwent surgical repair to determine early surgical intervention for ACS independently of a specific IVP measurements.

\section{Acknowledgments}

This study is unfunded and all authors declare no financial interest.

This original research was presented in abstract form in Italian language at the XVII Congress of Italian Society of Neonatology in Sorrento (Italy) October 2011.

\section{References}

1 Beck R, Halberthal M, Zonis Z, Shoshani G, Hayari L, Bar-Joseph G. Abdominal compartment syndrome in children. Pediatr Crit Care Med 2001;2:51-56
2 Diaz FJ, Fernandez Sein A, Gotay F. Identification and management of abdominal compartment syndrome in the pediatric intensive care unit. P R Health Sci J 2006;25:17-22

3 Ejike JC, Humbert S, Bahjri K, Mathur M. Outcomes of children with abdominal compartment syndrome. Acta Clin Belg Suppl 2007; (1):141-148

4 World Society of ACS (WSACS) consensus guidelines summary. Available at: http://www.WSACS.org. Accessed on July 4, 2012.

5 Sukhotnik I, Riskin A, Bader D, et al. Possible importance of increased intra-abdominal pressure for the development of necrotizing enterocolitis. Eur J Pediatr Surg 2009;19:307-310

6 Hong CM, Patel A. Novel intra-operative pulse oximetry monitoring for gastroschisis: a noninvasive monitor of intra-abdominal pressure. Paediatr Anaesth 2008;18:344-345

7 Mertens L, Seri I, Marek J, et al; Writing Group of the American Society of Echocardiography (ASE); European Association of Echocardiography (EAE); Association for European Pediatric Cardiologists (AEPC). Targeted neonatal echocardiography in the neonatal intensive care unit: practice guidelines and recommendations for training. Eur J Echocardiogr 2011;12:715-736

8 DeCou JM, Abrams RS, Miller RS, Gauderer MWL. Abdominal compartment syndrome in children: experience with three cases. J Pediatr Surg 2000;35:840-842

9 Neville HL, Lally KP, Cox CS Jr. Emergent abdominal decompression with patch abdominoplasty in the pediatric patient. J Pediatr Surg 2000;35:705-708

10 Bonnard A, Carricaburu E, Alberti C, et al. Is intraabdominal pressure a good predictor of mortality in necrotizing enterocolitis? Intensive Care Med 2010;36:551-552

11 Steinau G, Kaussen T, Bolten B, et al. Abdominal compartment syndrome in childhood: diagnostics, therapy and survival rate. Pediatr Surg Int 2011;27:399-405

12 Akhobadze GR, Chkhaidze MG, Kanjaradze DV, Tsirkvadze IB, Ukleba VA. Identification, management and complications of intra-abdominal hypertension and abdominal compartment syndrome in neonatal intensive care unit (a single centre retrospective analysis). Georgian Med News 2011;(192):58-64

13 Gerstmann DR, Null DM. Bladder pressure and intra-abdominal hypertension in sick neonates. Journal Neonatal-Perinatal Medicine 2010;3:301-305

14 Bertram P, Schachtrupp A, Rosch R, Schumacher O, Schumpelick V. [Abdominal compartment syndrome]. Chirurg 2006;77:573-574, 576-579

15 Suehiro K, Okutani R, Ogawa S, et al. Perioperative management of a neonate with Cantrell syndrome. J Anesth 2009;23:572-575

16 Düzgün AP, Gülgez B, Ozmutlu A, et al. The relationship between intestinal hypoperfusion and serum d-lactate levels during experimental intra-abdominal hypertension. Dig Dis Sci 2006; 51:2400-2403

17 Unsal MA, Imamoglu M, Kadioglu M, et al. The acute alterations in biochemistry, morphology, and contractility of rat-isolated terminal ileum via increased intra-abdominal pressure. Pharmacol Res 2006;53:135-141

18 Schachtrupp A, Lawong G, Afify M, Graf J, Toens C, Schumpelick V. Fluid resuscitation preserves cardiac output but cannot prevent organ damage in a porcine model during $24 \mathrm{~h}$ of intraabdominal hypertension. Shock 2005;24:153-158 